\title{
A majority of Brazilian patients with rheumatoid arthritis HLA-DRB 1 alleles carry both the HLA-DRB1 shared epitope and anti-citrunillated peptide antibodies
}

\author{
P. Louzada-J únior ${ }^{1}$, M.V.C. Freitas ${ }^{1}$, R.D.R. Oliveira ${ }^{1}$, N.H.S. Deghaide ${ }^{1}$, R.A. Conde ${ }^{2}$ \\ M.B. Bertolo ${ }^{2}$ and E.A. Donadi ${ }^{1}$ \\ 1Divisão de Imunologia Clínica, Departamento de Clínica Médica, Faculdade de Medicina de Ribeirão \\ Preto, Universidade de São Paulo, Ribeirão Preto, SP, Brasil \\ 2Disciplina de Reumatologia, Faculdade de Ciências Médicas, Universidade Estadual de Campinas, \\ Campinas, SP, Brasil
}

Correspondence to: P. Louzada-J únior, Divisão de Imunologia Clínica, Departamento de Clínica Médica, FMRP, USP, Av. Bandeirantes, 3900, 14048-900 Ribeirão Preto, SP, Brasil

Fax: +55-16-3633-6695. E-mail: plouzada@ fmrp.usp.br

\begin{abstract}
The objective of the present study was to evaluate the contribution of the shared epitope (SE), the rheumatoid arthritis (RA) protection model, and the occurrence of anti-cyclic citrullinated peptide (anti-CCP) antibodies in RA patients from a genetically diverse population. One hundred and forty Brazilian RA patients and 161 matched controls were typed for HLA-DRB1 alleles using amplified DNA hybridized with sequence-specific oligonucleotide probes or primers. Patients were stratified according to the presence or absence of SE (DRB $1 * 0401, * 0404, * 0405, * 0101, * 1001$, and *1402), of the DE RAA alleles (DRB $1 * 0103, * 0402$, $* 1102, * 1103, * 1301, * 1302$, and $* 1304$ ), and X (all other alleles). Anti-CCP antibodies were measured by ELISA. The combined frequency of SE-positive alleles was significantly greater $(76.4$ vs $23.6 \%, P<0.0001)$ than the controls. The SE/SE and SE/X genotypes were over-represented $(P<0.0001, O R=6.02)$ and $D E R A A / X$ was under-represented in $R A$ patients $(P<0.001,0 R$ $=0.49$ ), whereas the frequencies of the SE/DERAA, $X / X$ and X/DERAA genotypes were not significantly different from controls. The frequency of anti-CCP antibodies was higher in SE-positive patients than in SE-negative patients $(64.6 \mathrm{vs} 44.7 \%, \mathrm{P}=0.03$; $O R=2.25$ ). Although the Brazilian population is highly miscegenated, the results of this study support the findings observed in most genetically homogeneous populations with RA; however, they are not mutually exclusive but rather complementary. The participation of DRB1-DERAA alleles in protection against RA was also observed $(\mathrm{OR}=0.4 ; 95 \% \mathrm{Cl}=0.23-0.68)$.
\end{abstract}

Key words: Susceptibility to rheumatoid arthritis; HLA; Brazilians; Shared epitope; Anti-cyclic citrullinated peptide

Research supported by CNPq, Fundação de Apoio ao Ensino, Pesquisa e Assistência do Hospital das Clínicas de R ibeirão P reto (FAEPA). Publication supported by FAPESP.

Received August 8, 2007. Accepted May 7, 2008

\section{Introduction}

Several lines of evidence indicate the role of major histocompatibility complex class II molecules in the susceptibility to seropositive rheumatoid arthritis (RA), particularly the molecules encoded by HLA-DRB1 genes (1). DRB1 genes that confer susceptibility to RA include
DRB1*0401 and *0404 alleles among Caucasians $(2,3)$, DRB $1 * 0405$ in East Asian patients (4), DRB $1 * 0101$ in Asian Indians (5) and Ashkenazi J ews (6), DR B 1*1001 in Spaniards (7) and Blacks from South Africa (8), and DRB1*1402 in native North Americans (9). These RAassociated alleles share a nucleotide sequence encoding amino acid residues from position 67 to 74 of the third 
hypervariable region (HV3) of the DRß1 chain, a sequence that has been named the RA shared epitope (SE) $(10,11)$. The QRRAA sequence is found in molecules encoded by DRB1*0404,*0405,*0101,*1001, and *1402 alleles (sharing arginine at codon 71), and the QKRAA motif is observed in the DRB1*0401 allele (lysine at codon 71) (11).

In addition to the association of RA and SE-positive $\left(\mathrm{SE}^{+}\right)$alleles, $\mathrm{SE}$-negative ( $\mathrm{SE}^{-}$) alleles are also reported to influence susceptibility to RA by means of particular polymorphic anchor residue sequences present in one of the 5 peptide-binding pockets of the DRß1 chain, i.e., pockets $1,4,6,7$, and 9 (P1, P 4, P6, P 7, and P9). These pockets may influence the peptide-binding specificity of human leukocyte antigen (HLA) class II molecules, particularly P 4 (12). The SE-associated alleles contribute only 3 residues $(70,71$, and 74$)$ to form $P 4$, whereas the fourth residue is encoded in the first hypervariable region by codon 13. Alleles which have a neutral or negative electric charge in their P4, including DRB $1 * 0103, * 0402, * 07, * 08$, $* 11$ (except $* 1107), * 12$, and $* 13$, are reported to protect against the development of RA. In contrast, alleles that possess a positive electric charge in their $P 4$, such as DR B1*03, *0403,*0406, *0407,*0901,*1107, *14, *15, and $* 16$ alleles, have no influence on predisposition to RA $(12,13)$

According to the RA protection (RAP) model, a short amino acid sequence, ${ }^{70} \mathrm{DERAA}^{74}$, encoded by the HV3 of the DRB1*0103,*0402,*1102,*1103,*1301, 1302, and *1304 alleles confers protection against the development of RA. This model has been supported by several crosssectional studies among Caucasian RA patients (14-16).

Autoantibodies to cyclic citrullinated peptides (antiCCP antibodies) are highly specific for RA, can be detected years before the first clinical manifestation of $R A$ (17), and are reported to be a good predictor of the development of RA (18). Because the contribution of the SEcontaining HLA alleles to the pathogenesis of RA is not well understood, the novel information on the association of SE alleles with anti-CCP-positive disease (17) led us to evaluate the hypothesis that the SE alleles are a risk factor for anti-CCP antibodies.

Since the Brazilian population is genetically diverse, presenting a distinctive pattern of DR alleles and haplotypes, the evaluation of RA susceptibility models in this highly miscegenated population can contribute to the understanding of such associations. In the present study, we evaluated the contribution of DRB1 alleles stratified according to the clustering of $\mathrm{SE}^{+}$and $\mathrm{SE}^{-}$-alleles, the RAP model alleles and the presence of anti-CCP antibodies among Brazilian patients with RA.

\section{Subjects and Methods}

\section{Patients and controls}

A total of 140 (109 women) patients aged 24-79 years (median $=51$ ), including 98 Whites, self-described to be of Western and Southern European ancestry, 24 Mulattoes (Caucasian and Black admixtures), and 18 Blacks, historically of mostly Bantu, Benin and Senegal African ancestry (19) presenting RA were evaluated at the University Hospital of the Faculty of Medicine of R ibeirão P reto, R ibeirão Preto, SP, Brazil, and at the University Hospital of the Faculty of Medical Sciences of Campinas, Campinas, SP, Brazil. All patients were typed for HLA-DRB1 alleles and fulfilled the 1987 revised criteria of the American College of Rheumatology for the diagnosis of RA (20). As controls, we evaluated 161 randomly selected normal blood donors of similar ethnic background from the same geographical region (21), including 86 Whites, self-described to be of Western and Southern European ancestry, 47 Blacks (Black ancestry up to the third generation), historically of mostly Bantu, Benin and Senegal African ancestry, as reviewed by Figueiredo et al. (19), and 28 Mulatto (Caucasian and Black admixtures) individuals. The population assignments were made by the same investigator who asked the donors about their ancestry. All individuals were submitted to a medical examination that showed no evidence of previous underlying diseases, and presented negative serology for Chagas' disease, B- and C-hepatitis, and HIV infection. The study protocol was approved by the Ethics Committee of the Faculty of Medicine of Ribeirão P reto, University of $S$ ão $P$ aulo, and all subjects gave written informed consent to participate in the study.

\section{Autoantibody detection}

The detection of anti-CCP2 IgG antibodies was performed using commercially available ELISA kits containing synthetic peptides (Quanta Lite anti-CCP2 Inova, San Diego, USA). ELISA was performed according to manufacturer instructions. Serum samples presenting results $>20$ $\mathrm{U} / \mathrm{mL}$ were considered to be positive for the anti-CCP antibody. R heumatoid factor was evaluated in all patients by nephelometry.

\section{HLA-DRB1 typing}

HLA-DRB 1 alleles were characterized using polymerase chain reaction-amplified DNA hybridized to sequencespecific oligonucleotide probes, as previously described (22-24).

Allele clustering according to the SE and the RAP models The frequency of DRB 1 alleles considered to pertain to 
the SE was as the sum of the individual frequency of the DR B1*0101,*0102,*0401,*0404,*0405,*0408,*1001 and $* 1402$ alleles. Patients carrying one or two alleles of shared epitope were classified as SE-positive.

Protective DRB1 alleles (all carrying the HV3 motif DERAA) are the *0103,*0402,*1102,*1103,*1301 and *1302 alleles, which have been reported to be DERAA-positive alleles $(12,13)$. For clarity, this study uses the term DERAA-encoding alleles but does not differentiate between the direct effect of these alleles and the effect of other alleles in linkage with the DERAA-encoding alleles. For analysis, 6 groups were formed according to the presence of DRB1 alleles, as follows: group $A$, homozygosity for the SE (SE/SE); group B, 1 SE allele and 1 no SE and no DERAA (SE/X); group C, 1 SE and 1 DERAA allele (SE/DERAA); group D, no SE and no DERAA $(X / X)$; group $E, 1$ DERAA allele (X/DERAA), and group $F$, homozygosity for DERAA alleles (DERAA/DERAA) (see Table 2).

\section{Statistical analysis}

HLA frequencies observed in patients and controls were compared using the two-tailed Fisher exact test with the approximation of Woolf. Differences were considered to be significant at $P<0.05$. The odds ratio (OR) was used to estimate the strength of the associations. The detection of the strongest association between alleles was performed by the method of Svejgaard and Ryder (25). The variables (gender, race, age) observed in patients and controls were compared using unpaired $t$-test. Differences were considered to be significant at $P<0.05$.

\section{Results}

\section{Frequencies of DRB1 and DRB1 alleles clustered as SE and DERAA alleles}

The individual comparison of the frequency of the HLA alleles associated with RA, i.e., the HLA-DR B 1*0401, *0404 (*0408), *0405, *0101, and $* 1001$ alleles, observed in this series was significantly different from the respective frequency observed in controls (Table 1). Nevertheless, when the frequency of the SE alleles was considered, it was observed in $39.6 \%$ of RA patients and in only $12.5 \%$ of the controls
(PC $<0.0001 ;$ Table 1), with an OR of 6.02. The frequency of DERAA alleles in RA patients was decreased when compared with controls ( 11.42 vs $20.8 \%, P=0.003, O R=$ 0.49 ), conferring protection against the development of $R A$ (Table 1).

Table 1. DRB 1 and shared epitope (SE) allele frequencies among patients with rheumatoid arthritis (RA) and controls.

\begin{tabular}{|c|c|c|c|c|}
\hline DRB 1 & $\begin{array}{c}\text { Controls } \\
(\mathrm{N}=312 \text { alleles })\end{array}$ & $\begin{array}{l}\text { R heumatoid arthritis } \\
\quad(\mathrm{N}=280 \text { alleles })\end{array}$ & OR & $95 \% \mathrm{Cl}$ \\
\hline *0101 & $14(4.35 \%)$ & $34(12.1 \%)^{*}$ & 2.94 & $1.54-5.60$ \\
\hline *0102 & $9(2.8 \%)$ & $0(0 \%)$ & & \\
\hline$* 0103$ & $1(0.3 \%)$ & $0(0 \%)$ & & \\
\hline *1501 & $29(10.35 \%)$ & $21(10.1 \%)$ & & \\
\hline$* 1502$ & $4(1.25 \%)$ & $2(0.7 \%)$ & & \\
\hline *1601 & $9(2.8 \%)$ & $9(3.2 \%)$ & & \\
\hline *1602 & $4(1.25 \%)$ & $4(1.4 \%)$ & & \\
\hline *0301 & $35(10.85 \%)$ & $25(8.9 \%)$ & & \\
\hline *0302 & $7(2.15 \%)$ & $2(0.7 \%)$ & & \\
\hline *0401 & $6(1.85 \%)$ & $21(7.5 \%)^{*}$ & 4.25 & $1.69-10.67$ \\
\hline$* 0402$ & $4(1.25 \%)$ & $4(1.4 \%)$ & & \\
\hline$* 0403$ & $3(0.9 \%)$ & $2(0.7 \%)$ & & \\
\hline *0404 & $7(4.3 \%)$ & $21(7.5 \%)^{*}$ & 6.40 & $2.17-18.90$ \\
\hline *0405 & $4(1.25 \%)$ & $13(4.7 \%)^{*}$ & 3.84 & $1.24-11.94$ \\
\hline *0406 & $1(0.3 \%)$ & $0(0 \%)$ & & \\
\hline *0407 & $7(2.15 \%)$ & $0(0 \%)$ & & \\
\hline *0411 & $7(2.15 \%)$ & $2(0.7 \%)$ & & \\
\hline *1101 & $19(5.8 \%)$ & $7(2.5 \%)^{*}$ & 0.39 & $0.16-0.95$ \\
\hline *1102 & $9(2.8 \%)$ & $5(1.8 \%)$ & & \\
\hline *1103 & $4(1.25 \%)$ & $2(0.7 \%)$ & & \\
\hline *1104 & $11(3.4 \%)$ & $8(2.8 \%)$ & & \\
\hline *1105 & $2(0.6 \%)$ & $0(0 \%)$ & & \\
\hline *1201 & $5(1.55 \%)$ & $5(1.8 \%)$ & & \\
\hline *1202 & $1(0.3 \%)$ & $0(0 \%)$ & & \\
\hline *1301 & $22(6.85 \%)$ & $12(4.3 \%)$ & & \\
\hline *1302 & $21(6.55 \%)$ & $12(4.3 \%)$ & & \\
\hline *1303 & $2(0.6 \%)$ & $0(0 \%)$ & & \\
\hline$* 1304$ & $1(0.3 \%)$ & $1(0.35 \%)$ & & \\
\hline *1401 & $12(3.7 \%)$ & $5(1.8 \%)$ & & \\
\hline *1402 & $3(0.9 \%)$ & $6(2.15 \%)$ & & \\
\hline *07 & $27(8.4 \%)$ & $23(6.45 \%)$ & & \\
\hline *0801 & $5(1.55 \%)$ & $5(1.8 \%)$ & & \\
\hline *0802 & $3(0.9 \%)$ & $1(0.35 \%)$ & & \\
\hline *0804 & $7(2.15 \%)$ & $2(0.7 \%)$ & & \\
\hline$* 0807$ & $5(1.55 \%)$ & $0(0 \%)$ & & \\
\hline$* 09$ & $7(2.15 \%)$ & $10(3.55 \%)$ & & \\
\hline *10 & $5(1.55 \%)$ & $16(5.7 \%)^{*}$ & 4.38 & $1.58-12.15$ \\
\hline SE-positive & $39(12.5 \%)$ & $111(39.6 \%)^{*}$ & 6.02 & $3.95-9.17$ \\
\hline DERAA-positive & $65(20.8 \%)$ & $32(11.42 \%)^{*}$ & 0.49 & $0.31-0.77$ \\
\hline
\end{tabular}

Data are reported as number with percent in parentheses unless otherwise stated. SE-positive alleles: DRB1*0101, *0102,*0401, *0404 $(* 0408), * 0405$, $* 1001$ and *1402 alleles; DERAA-positive alleles: DRB1*0103, *0402, *1102, $* 1103, * 1301$ and $* 1302$ alleles. OR $=$ odds ratio; $95 \% \mathrm{Cl}=$ confidence interval at $95 \%$. HLA frequencies observed in patients and controls were compared using the two-tailed Fisher exact test with the approximation of Woolf. Differences were considered to be significant at $P<0.05$. 
Table 2. DRB1 genotype frequencies according to the presence of predisposing alleles (SE alleles) and protection alleles in rheumatoid arthritis (RA) patients and controls.

\begin{tabular}{llcc}
\hline Group & DRB1 genotype & RA $(\mathrm{N}=140)$ & Controls $(\mathrm{N}=161)$ \\
\hline A & SE/SE & $26(18.6 \%)$ & $6(3.7 \%)$ \\
B & SE/X & $57(40.7 \%)$ & $25(15.5 \%)$ \\
C & SE/DERAA & $10(7.1 \%)$ & $10(6.2 \%)$ \\
D & X/X & $30(21.4 \%)$ & $70(43.5 \%)$ \\
E & X/DERAA & $12(8.6 \%)$ & $45(28.0 \%)$ \\
F & DERAA/DERAA & $5(3.6 \%)$ & $5(3.1 \%)$ \\
\hline
\end{tabular}

Data are reported as number of individuals with percent within parentheses. The shared epitope (SE) alleles are $* 0101, * 0102$, $* 0401, * 0404, * 0405, * 0408, * 1001$ and $* 1402$. The DERAA alleles are DRB $1 * 0103, * 0402, * 1102, * 1103, * 1301, * 1302$ and *1304. X $=$ represents all other DRB1 alleles. Groups were formed according to the presence of DRB1 alleles, as follows: group A, homozygosity for the SE (SE/SE); group B, 1 SE allele and 1 no $S E$ and no DERAA (SE/X); group $C, 1 \mathrm{SE}$ and 1 DERAA allele (SE/DERAA); group D, no SE and no DERAA (X/ $X)$; group $E, 1$ DERAA allele (X/DERAA), and group $F$, homozygosity for DERAA alleles (DERAA/DERAA).

Table 3. Demographic data and laboratory features of the Brazilian rheumatoid arthritis patients in the present study $(\mathrm{N}=140)$.

\begin{tabular}{lcc}
\hline Variables & RA $(\mathrm{N}=140)$ & Controls $(\mathrm{N}=161)$ \\
\hline Gender & & \\
$\quad$ Female & $109(77.8 \%)$ & $120(74.5 \%)$ \\
$\quad$ Male & $31(22.2 \%)$ & $41(25.5 \%)$ \\
Race & $98(70 \%)$ & $86(53.4 \%)$ \\
$\quad$ White & $24(17.1 \%)$ & $28(17.4 \%)$ \\
Mulatto & $18(12.9 \%)$ & $47(29.2 \%)$ \\
$\quad$ Black & $50.41 \pm 11.28 *$ & $35.5 \pm 8.4$ \\
Age (years, mean \pm SD) & 50 & 34 \\
median & $24-78$ & $22-45$ \\
minimum-maximum & $38.5 \pm 11.2$ & $\mathrm{NA}$ \\
Age at onset of disease & & \\
(years, mean \pm SD) & $17-57$ & $\mathrm{NA}$ \\
minimum-maximum & $9.49 \pm 8.44$ & \\
Time of disease (years, & & \\
mean \pm SD) & 10.5 & $\mathrm{ND}$ \\
median & $1-38$ & $\mathrm{ND}$ \\
minimum-maximum & $81(58 \%)$ & $39(12.5 \%)$ \\
Anti-CCP-positive & $85(60.7 \%)$ & \\
R F-positive & $93(66.4 \%)$ & \\
SE-positive &
\end{tabular}

Data are reported as number of individuals with percent in parentheses unless otherwise stated. RA = rheumatoid arthritis; Anti$C C P=$ anti-cyclic citrullinated peptide antibodies; $R F=$ rheumatoid factor; SE = shared epitope; $N A=$ not applicable; ND = not determined. The variables (gender, race, age) observed in patients and controls were compared using unpaired $t$-test. Differences were considered to be significant at $P<0.05$. SE-positive observed in patients and controls were compared using the twotailed Fisher exact test with the approximation of Woolf. Differences were considered to be significant at $\mathrm{P}<0.05$ (*P $<$ $0.0001)$.
DERAA-positive alleles (RAP model), and the influence of the SE

To study the effect of the presence of the DERAA motif on susceptibility to $R A$, patients and controls were divided into 6 groups according to their HLA-DRB1 genotypes (Table 2). The overall effect of DERAA on the development of RA was assessed by comparing the presence of the DERAA motif (groups $C, E$, and $F$ ) versus its absence (groups $A, B$, and D). The presence of DERAA was underrepresented in the RA patients $(19.3 \%)$ versus controls $(37.2 \%)$, conferring an $O R$ of $0.40(P=0.0006 ; 95 \% \mathrm{Cl}=$ 0.23-0.68). The effect of the DERAA on the absence of the $S E$ alleles was assessed by comparing group $E$ (X/DERAA) plus group $F$ (DERAA/DERAA) with group $D(X / X)$. DERAA subjects had a reduced risk of developing $R A(O R=0.7)$, although the observed effect was not statistically significant $(P=0.6 ; 95 \% \mathrm{Cl}=0.39-1.59)$.

\section{Association between SE individuals and presence of anti-CCP antibodies}

Anti-CCP antibody was present in $58 \%$ of the patients and rheumatoid factor was present in $60.7 \%$. All patients with positive anti-CCP antibody also presented positive rheumatoid factor. Ninety-three patients carried at least one dose of shared epitope (Table 3). The frequency of anti-CCP antibodies was higher in SE-positive patients $(64.5 \%)$ when compared with SE-negative patients $(44.7 \%$; $P=0.03, O R=2.63$; see Table 4). The distribution of antiCCP antibodies was analyzed according to specific SErelated alleles; we did not observe a higher frequency of anti-CCP antibodies in RA patients carrying DRB $1 * 0401$, $* 0404$, and *0101 compared with patients who do not carry these alleles.

Table 4. Association of HLA-DRB1 shared epitope (SE) alleles and anti-cyclic citrullinated peptide (anti-CCP) antibodies in rheumatoid arthritis $(\mathrm{N}=140)$.

\begin{tabular}{lcccc}
\hline SE status & $\begin{array}{c}\text { Anti-CCP- } \\
\text { positive }\end{array}$ & $\begin{array}{c}\text { Anti-CCP- } \\
\text { negative }\end{array}$ & $\begin{array}{c}\text { OR } \\
(95 \% \mathrm{Cl})\end{array}$ & $\mathrm{P}$ \\
\hline SE-positive & $60(64.5 \%)$ & $33(35.5 \%)$ & $2.25(1.1-4.6)$ & 0.03 \\
SE-negative & $21(44.7 \%)$ & $26(55.3 \%)$ & &
\end{tabular}

Data are reported as number of individuals with percent in parentheses unless otherwise stated. Presence or not of anti-CCP antibodies in SE-positive or SE-negative RA patients was compared using the two-tailed Fisher exact test with the approximation of Woolf. Differences were considered to be significant at $P$ $<0.05$. 


\section{Discussion}

The association between RA and HLA-DR 4 antigens was first reported in the 1970s using cellular techniques (1), and has recently been reexamined at the genomic DNA level $(2,3)$. The susceptibility to RA has been reported to vary according to the ethnic background of the patients, supporting the "shared epitope" hypothesis $(10,11)$. The extraordinary genetic diversity of HLA alleles and haplotypes seen in highly miscegenated populations may result from the aggregation of distinctive alleles from separate racial and ethnic groups. The gene bank of the modern Brazilian population represents the contribution of individuals of varied racial and ethnic groups. Historic immigrations from Europe have distributed various Caucasian populations, mainly Portuguese, Spanish, Italian and German, across Brazil. Brazilian Amerindian populations still exist as semi-isolated tribal groups, but their genes are also represented in modern urban populations. In a previous study, we observed that the frequencies of DRB $1 * 15$ / $16(* 02), * 03, * 12, * 13$, and $* 09$ were similar among Whites, Blacks and Mulattoes. In contrast, the frequencies of DRB1*01,*04,*07,*08,*11, and *14 varied between the different groups. In particular, DRB $1 * 01$ genes were detected at approximately the same frequency in Whites and Mulattoes, but were greater in Blacks. DR B1*04 was similar in Whites and Mulattoes, but less in Blacks. Regarding the frequency of individual alleles, HLA-DRB $1 * 0101$ and *1001 were significantly greater in Blacks compared with Whites ( $P C=0.01$ and $P C=0.01$, respectively). The polymorphism of DR B $1 * 04$ alleles seen in Brazilian Whites was greater than that observed in the Black population (21). Since the DRB1*04,*01 and *10 allelic frequencies are different for White and Black individuals, Pina et al. performed a study on RA patients using exclusively AfroBrazilian descendants ( $P$ ina FP, Conde RC, LouzadaJ únior $\mathrm{P}$, Donadi $\mathrm{EA}, \mathrm{B}$ ertolo $\mathrm{MB}$, unpublished data). They concluded that Afro-Brazilians with RA inherited a few HLA genes, which are characteristic of RA not only in African people, but also in Europeans and Asians who originated the Brazilian population. In Chile, where HLA-DR 4 encoding DRB1 alleles do not encode susceptibility to RA (26), HLA-DR 9 was associated with RA (27). In Japan, DRB1*0901 was associated with RA after exclusion of alleles $* 0101$ and $* 0405$ (28). In Kuwait, the association of HLA-DR 3 with RA is explained by a high frequency of HLADR 3 together with a relatively low frequency of HLA-DR 4 alleles (29). In the present study, we did not observe an association with either DRB1-09 or DRB1-03 alleles. In fact, all DRB1 SE alleles were observed in Brazilian RA patients, including the rare DRB $1 * 1402$ allele that is com- monly observed in individuals of Amerindian heritage, reflecting the high diversity of the population of the present study (21). Thus, in highly miscegenated populations the evaluation of SE frequency instead of individual alleles pertaining to the SE may be more important in terms of immunogenetic susceptibility to RA.

The events involved in the pathogenesis of RA are still unclear, but certainly the etiology is multifactorial. The shared epitope of HLA-DRB1 is the most important genetic risk factor. Environmental risk factors are less understood. Smoking is a candidate, associated with increased citrullinated cyclic peptide antibodies (30-32). In this study, we investigated the associations between HLA class II alleles and RA and the protective effects of the DERAA-encoding HLA-DRB1 alleles on RA susceptibility. The question of whether the effect of DERAA is truly protective or is merely the result of the absence of predisposing SE encoding HLA-DRB 1 alleles is the subject of some controversy. In the present study, the comparison of subgroups (Table 2) allowed differentiation of the effects of protection and nonprotection. In addition, in our population, we showed that DERAA-encoding HLA-DRB1 alleles independently reduce the risk of developing $R A$. These findings agree with similar results observed in more homogeneous groups such as Dutch (13) and Swiss (33) populations.

It has been demonstrated that peptides carrying the DERAA motif are naturally processed by human antigenpresenting cells, and it has been suggested that the protective effect of DERAA is mediated by a specific protective $T$ cell response (34). Although our results show that the presence of a predisposing haplotype is not required to observe the protective effect associated with DERAA, it is possible that the DERAA sequence, particularly the DRB $1 * 13$ alleles, not only protects against RA but is also associated with a milder outcome in other diseases, such as reduced progression to active chronic hepatitis $C$ and $B$ (35). Theses findings are intriguing and indicate the importance of elucidating the biologic pathways underlying these associations, because they might unveil new insight into immune regulation in relation to the HLA system.

What does this tell us about the disease mechanism? Assuming differential risks for no susceptibility alleles, this hypothesis is able to explain data in the literature by referring to mutations in amino acid sequence at positions 67-74 in the HLA-DRB1 molecule. Thus, this version supports the notion that this sequence is central in conferring susceptibility to RA and does not indicate a role for another gene within the HLA complex. The fact that local amino acid substitutions induce differential risks suggests that the interaction of this region with presented peptides, superantigens or invariant chain may be important in the 
pathogenesis of this disease $(13,14)$.

We observed a higher frequency of anti-CCP antibodies in SE-positive patients (64.5\%) compared with SEnegative patients $(44.7 \%)$. In contrast, we did not observe a higher frequency of anti-CCP antibodies in RA patients that carried specific SE-related alleles, such as DR B 1*0401, $* 0404$, and $* 0101$. Huizinga et al. (17) reported that the SE alleles were only associated with anti-CCP-positive RA and not with anti-CCP-negative disease, indicating that the SE alleles are not associated with RA as such, but rather with a distinct phenotype of the disease. Although no formal conclusions on causality can be drawn from this association study, these findings suggest that anti-CCP antibodies mediate the association between $\mathrm{SE}$ alleles and RA (36). It would be of interest to repeat the present study by following the development of anti-CCP antibodies and RA in healthy asymptomatic persons with and without SE alleles. Nevertheless, the present findings constitute an important refinement of the long-known association between HLA and RA by indicating that the SE alleles are

\section{References}

1. Stastny P. Mixed lymphocyte cultures in rheumatoid arthritis. J Clin Invest 1976; 57: 1148-1157.

2. Nepom GT, Seyfried CE, Holbeck SL, Wilske KR, Nepom BS. Identification of HLA-Dw14 genes in DR 4+ rheumatoid arthritis. Lancet 1986; 2: 1002-1005.

3. Wordsworth BP, Lanchbury J S, Sakkas LI, Welsh KI, Panayi GS, Bell JI. HLA-DR4 subtype frequencies in rheumatoid arthritis indicate that DRB1 is the major susceptibility locus within the HLA class II region. Proc Natl Acad Sci U S A 1989; 86: 10049-10053.

4. Ohta N, Nishimura YK, Tanimoto K, Horiuchi Y, Abe C, Shiokawa $Y$, et al. Association between HLA and J apanese patients with rheumatoid arthritis. Hum Immunol 1982; 5: 123-132.

5. Nichol FE, Woodrow J C. HLA DR antigens in Indian patients with rheumatoid arthritis. Lancet 1981; 1: 220-221.

6. Schiff B, Mizrachi Y, Orgad S, Yaron M, Gazit E. Association of HLA-Aw31 and HLA-DR 1 with adult rheumatoid arthritis. Ann Rheum Dis 1982; 41: 403-404.

7. Sanchez B, Moreno I, Magarino R, Garzon M, Gonzalez MF, Garcia A, et al. HLA-DRw10 confers the highest susceptibility to rheumatoid arthritis in a Spanish population. Tissue Antigens 1990; 36: 174-176.

8. Pile KD, Tikly M, Bell JI, Wordsworth BP. HLA-DR antigens and rheumatoid arthritis in black South Africans: a study of ethnic groups. Tissue Antigens 1992; 39: 138-140.

9. Willkens RF, Nepom GT, Marks CR, Nettles JW, Nepom BS. Association of HLA-Dw16 with rheumatoid arthritis in Yakima Indians. Further evidence for the "shared epitope" hypothesis. Arthritis Rheum 1991; 34: 43-47.

10. Gregersen PK, Silver J, Winchester RJ. The shared epitope hypothesis. An approach to understanding the molecular genetics of susceptibility to rheumatoid arthritis. Arthritis not primarily associated with $\mathrm{RA}$, but rather with anti-CCP antibody positivity.

Although SE represents the major contribution to RA susceptibility, other genes acting individually or in concert with SE may also be involved $(37,38)$. In addition, environmental factors may further induce epigenetic alterations contributing to RA pathogenesis $(39,40)$.

We have presented several lines of evidence indicating the involvement of DRB 1 alleles in the susceptibility to RA. The RAP, SE and P4 polymorphism models are all associated with the HV3 region of the DRB1 gene and are useful to understand the immunogenetic susceptibility to RA. The findings of the present study support current RA models, and also support the idea that these models are not mutually exclusive but rather complementary as proposed by Zanelli et al. (16). Even though the Brazilian population is highly miscegenated, overall the present findings agree with others observed in genetically more homogeneous populations.

Rheum 1987; 30: 1205-1213.

11. de Vries N, Tijssen $H$, van Riel PL, van de Putte LB. Reshaping the shared epitope hypothesis: HLA-associated risk for rheumatoid arthritis is encoded by amino acid substitutions at positions 67-74 of the HLA-DRB1 molecule. Arthritis Rheum 2002; 46: 921-928.

12. Seidl C, Korbitzer J, Badenhoop K, Seifried E, Hoelzer D, Zanelli $E$, et al. Protection against severe disease is conferred by DERAA-bearing HLA-DRB1 alleles among HLADQ 3 and HLA-DQ5 positive rheumatoid arthritis patients. Hum Immunol 2001; 62: 523-529.

13. van der Helm-van Mil AH, Huizinga TW, Schreuder GM, Breedveld FC, de Vries RR, Toes RE. An independent role of protective HLA class II alleles in rheumatoid arthritis severity and susceptibility. Arthritis R heum 2005; 52: 26372644.

14. Mattey DL, Dawes PT, Gonzalez-Gay MA, Garcia-Porrua $C$, Thomson W, Hajeer AH, et al. HLA-DRB1 alleles encoding an aspartic acid at position 70 protect against development of rheumatoid arthritis. J Rheumatol 2001; 28: 232239.

15. Reviron D, Perdriger A, Toussirot $E$, Wendling D, Balandraud N, Guis S, et al. Influence of shared epitope-negative HLA-DRB1 alleles on genetic susceptibility to rheumatoid arthritis. Arthritis Rheum 2001; 44: 535-540.

16. Zanelli E, Breedveld FC, de Vries RR. HLA class II association with rheumatoid arthritis: facts and interpretations. Hum Immunol 2000; 61: 1254-1261.

17. Huizinga TW, Amos $\mathrm{Cl}$, van der Helm-van Mil AH, Chen W, van Gaalen FA, J awaheer $D$, et al. Refining the complex rheumatoid arthritis phenotype based on specificity of the HLA-DRB1 shared epitope for antibodies to citrullinated proteins. Arthritis Rheum 2005; 52: 3433-3438. 
18. Rantapaa-Dahlqvist $S$, de J ong BA, Berglin $E$, Hallmans $G$, Wadell $G$, Stenlund $H$, et al. Antibodies against cyclic citrullinated peptide and IgA rheumatoid factor predict the development of rheumatoid arthritis. Arthritis Rheum 2003; 48: 2741-2749.

19. Figueiredo MS, Silva MC, Guerreiro J F, Souza GP, Pires $A C$, Zago MA. The heterogeneity of the beta s cluster haplotypes in Brazil. Gene Geogr 1994; 8: 7-12.

20. Arnett FC, Edworthy SM, Bloch DA, McShane DJ, Fries J F, Cooper NS, et al. The American R heumatism Association 1987 revised criteria for the classification of rheumatoid arthritis. Arthritis R heum 1988; 31: 315-324.

21. Louzada-J unior P, S mith AG, Hansen J A, Donadi EA. HLADRB1 and -DQB1 alleles in the Brazilian population of the northeastern region of the State of São Paulo. Tissue Antigens 2001; 57: 158-162.

22. Mickelson E, S mith A, McKinney S, Anderson G, Hansen J A. A comparative study of HLA-DRB1 typing by standard serology and hybridization of non-radioactive sequencespecific oligonucleotide probes to PCR-amplified DNA. Tissue Antigens 1993; 41: 86-93.

23. Kimura A, Sasazuki T. Eleventh International Histocompatibility Workshop reference protocol for the HLA DNAtyping technique. In: Tsuji K, Aizawa M, Sasazuki T (Editors), HLA 1991. Proceedings of the Eleventh International Histocompatibility Workshop Conference held in Yokohoma, Japan, November 6-13. Oxford: Oxford Science Publications; 1992. p 397-419.

24. Olerup 0 , Zetterquist $H$. HLA-DR typing by $P C R$ amplification with sequence-specific primers (PCR-SSP) in 2 hours: an alternative to serological DR typing in clinical practice including donor-recipient matching in cadaveric transplantation. Tissue Antigens 1992; 39: 225-235.

25. Svejgaard A, Ryder LP. HLA and disease associations: detecting the strongest association. Tissue Antigens 1994; 43: 18-27.

26. Massardo L, J acobelli $S$, Rodriguez $L$, Rivero $S$, Gonzalez A, Marchetti R. Weak association between HLA-DR 4 and rheumatoid arthritis in Chilean patients. Ann Rheum Dis 1990; 49: 290-292.

27. Massardo L, Aguirre V, Garcia ME, Cervila V, Nicovani S, Gonzalez A, et al. Clinical expression of rheumatoid arthritis in Chilean patients. Semin Arthritis Rheum 1995; 25: 203213.

28. Wakitani S, Imoto K, Murata N, Toda Y, Ogawa R, Ochi T. The homozygote of HLA-DRB1*0901, not its heterozygote, is associated with rheumatoid arthritis in J apanese. Scand J R heumatol 1998; 27: 381-382.

29. Sattar MA, al-Saffar M, Guindi RT, Sugathan TN, White AG,
Behbehani K. Histocompatibility antigens (A, B, C, and DR) in Arabs with rheumatoid arthritis. Dis Markers 1990; 8: 1115.

30. Padyukov L, Silva C, Stolt P, Alfredsson L, Klareskog L. A gene-environment interaction between smoking and shared epitope genes in HLA-DR provides a high risk of seropositive rheumatoid arthritis. Arthritis Rheum 2004; 50: 30853092.

31. Linn-Rasker SP, van der Helm-van Mil AH, van Gaalen FA, Kloppenburg $M$, de Vries RR, le Cessie $S$, et al. Smoking is a risk factor for anti-CCP antibodies only in rheumatoid arthritis patients who carry HLA-DRB1 shared epitope alleles. Ann Rheum Dis 2006; 65: 366-371.

32. Oliveira RD, J unta CM, Oliveira FR, Silva LM, Donadi EA, Louzada-J unior $P$. Share epitope, citrullinated cyclic peptide antibodies and smoking in Brazilian rheumatoid arthritis patients. Clin Rev Allergy Immunol 2008; 34: 32-35.

33. Zanelli E, Huizinga TW, Guerne PA, Vischer TL, Tiercy J M, Verduyn W, et al. An extended HLA-DQ-DR haplotype rather than DRB 1 alone contributes to RA predisposition. Immunogenetics 1998; 48: 394-401.

34. Snijders A, Elferink DG, Geluk A, van Der Zanden AL, Vos $K$, Schreuder GM, et al. An HLA-DRB1-derived peptide associated with protection against rheumatoid arthritis is naturally processed by human APCs. J Immunol 2001; 166: 4987-4993.

35. Hohler T, Gerken G, Notghi A, Knolle P, Lubjuhn R, Taheri $H$, et al. MHC class II genes influence the susceptibility to chronic active hepatitis C. J Hepatol 1997; 27: 259-264.

36. van der Helm-van Mil AH, Verpoort KN, Breedveld FC, Huizinga TW, Toes RE, de Vries RR. The HLA-DRB1 shared epitope alleles are primarily a risk factor for anti-cyclic citrullinated peptide antibodies and are not an independent risk factor for development of rheumatoid arthritis. Arthritis Rheum 2006; 54: 1117-1121.

37. Verpoort KN, Cheung K, loan-Facsinay A, van der Helmvan Mil AH, de Vries-Bouwstra J K, Allaart CF, et al. Fine specificity of the anti-citrullinated protein antibody response is influenced by the shared epitope alleles. Arthritis Rheum 2007; 56: 3949-3952.

38. Yamada R, Yamamoto K. Mechanisms of disease: genetics of rheumatoid arthritis - ethnic differences in disease-associated genes. Nat Clin Pract R heumatol 2007; 3: 644-650.

39. Gaston J S. Cytokines in arthritis - the 'big numbers' move centre stage. Rheumatology 2008; 47: 8-12.

40. Criswell LA, Saag KG, Mikuls TR, Cerhan J R, Merlino LA, Lum RF, et al. Smoking interacts with genetic risk factors in the development of rheumatoid arthritis among older Caucasian women. Ann Rheum Dis 2006; 65: 1163-1167. 